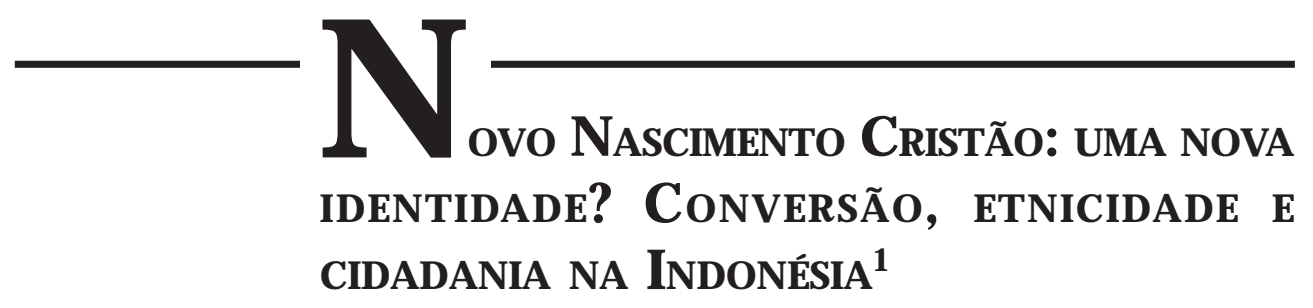

Juliette Koning

\title{
Introdução
}

Benny Hinn, tele-evangelista cristão que propõe a cura pela fé, fez uma turnê por várias cidades da Indonésia no final de março. Mais de 100.000 seguidores pagaram mais de US\$100 cada um para ouvir, erguendo os braços, seus sermões eletrizantes e para testemunhar aleijados levantarem de suas cadeiras de rodas. A Indonésia, que abriga uma das maiores populações muçulmanas do mundo, pode parecer um local pouco apropriado para Hinn. M as as principais cidades da Indonésia fazem parte do circuito evangélico internacional, e as igrejas protestantes carismáticas ${ }^{2}$ estão crescendo rapidamente. 0 s muçulmanos da Indonésia não demonstram interesse por $\mathrm{H}$ inn e pelos demais pregadores cristãos. Mas os chineses, em termos étnicos, da Indonésia, que são urbanos e ricos, aderem em massa ao cristianismo. Desde os anos 1950, quando somente uma pequena elite era cristã, vários milhões de chineses abandonaram as religiões tradicionais chinesas em favor do cristianismo, no mais das vezes para entrarem em igrejas evangélicas protestantes. Bem mais de $70 \%$ dos estimados 5 milhões, que constituem uma população 
etnicamente chinesa na Indonésia, são agora cristãos. A s igrejas carismáticas efervescentes e incrivelmente ricas crescem com uma mensagem de auto-confiança e sucesso material que parece atrair especialmente os jovens chineses. [Roderick Brazier, International Herald Tribune - Quinta-feira, 26 de abril de 2006]

D uas são as características principais dos chineses étnicos no exterior: são alvo de discriminação e são super-representados (em relação aos moradores locais no país de destino) nas estatísticas de auto-emprego e de empreendedorismo (Chan Kwok-bun 2004:xiii).

0 cristianismo pentecostal-carismático está crescendo rapidamente na Á sia. Países como Cingapura, China, Hong Kong, Taiwan, Indonésia e M alásia têm as comunidades cristãs que mais crescem no mundo, e a maioria dos novos crentes é constituída por (jovens) chineses de classe média, em ascensão social, de centros urbanos da Á sia (Brazier 2006; Vatikiotis 2005; Yang 2005). A ssim, a Ásia concentra hoje o segundo maior contingente de cristãos pentecostaiscarismáticos de todos os continentes, com um pico de crescimento entre 1970 e 2000, quando o número de seguidores cresceu de 10 a 135 milhões (Burgess 2002:301) ${ }^{3}$. Esse movimento levanta duas questões: porque acontece em tão larga escala na Á sia (hoje) e porque são especialmente os chineses, em termos étnicos, atraídos pelo cristianismo pentecostal-carismático? N este artigo, tentarei responder a essas questões relacionadas centrando minha atenção em um dos países que conhece um crescimento carismático "exponencial", a Indonésia. Colocando a questão em outros termos: qual é o apelo específico do cristianismo pentecostal-carismático para os grupos étnicos chineses na Indonésia, conhecidos pelo histórico de verem contestadas suas identidades cultural, política e econômica?

Embora a Indonésia seja um dos maiores países muçulmanos do mundo, o censo nacional de 2000 mostra que o crescimento anual dos cristãos, de 2,5\%, é um pouco superior ao crescimento de 1,9\% registrado para a população muçulmana (Siddique 2003). 0 país tem o maior número absoluto de pentecostais na região, avaliado entre 9 e 12 milhões, o que corresponde a $5 \%$ da população total (A nderson 2004b:130; Robinson 2005:340). Q uantos desses exatamente são de descendência chinesa é uma questão não resolvida; alguns afirmam que a proporção chega a $70 \%$ (como no artigo supracitado), enquanto outros registram simplesmente 0 fato de que a comunidade cristã na Indonésia é formada em grande parte pela etnia chinesa (Goh 2004:7).

O s chineses da Indonésia são uma minoria em termos étnicos e religiosos, uma vez que a maioria da população é muçulmana e malaia, no entanto dominam a economia. Circunstâncias históricas fizeram com que os de etnia chinesa 
sejam encontrados muito freqüentemente em ocupações de empreendedorismo ou de negócios, uma vez que não lhes era permitido ocupar cargos no serviço público ou possuir terras. Diz-se que os chineses controlam entre 70 e $75 \%$ das empresas privadas (não estatais) de médio e grande porte (Hefner 1998:17). A posição da população de etnia chinesa na Indonésia é freqüentemente contestada: a história mostrou por diversas vezes que durante períodos de conturbação política ou econômica eles são escolhidos como bodes expiatórios. N essa tradição de perseguição, o registro mais recente é de maio de 1998, quando o país enfrentava uma crise econômica importante junto com distúrbios políticos. Em várias grandes cidades, lojas e casas de chineses étnicos foram queimadas, e várias mulheres chinesas foram estupradas (cf. Susanto 2006). U ma grande parte dessa aversão contra os chineses está relacionada com sua posição econômica e com a idéia estereotipada de que eles são todos "extremamente ricos".

0 objeto de estudo do presente trabalho é portanto constituído pelos cidadãos etnicamente chineses - envolvidos principalmente em setores de negócios na economia, e confrontados a um histórico de assédio - que escolhem ativamente a conversão ao cristianismo carismático ${ }^{4}$. U sando a abordagem narrativa e observando as histórias de conversão, pretendo descortinar os modos pelos quais o cristianismo carismático se relaciona com as "identidades" pessoais e profissionais dos chineses étnicos, levando em conta os contextos mais amplos, nacional e global.

Inicialmente, discutirei a metodologia adotada para a pesquisa, passando em seguida para uma breve apresentação contextualizada da posição sociopolítica e socioeconômica dos chineses étnicos no Estado-nação indonésio, uma vez que essa posição pode estar relacionada com a escolha que eles fazem a respeito de seu engajamento nesse Estado-nação. Como é para o cristianismo carismático que eles se voltam, a seção seguinte tratará rapidamente das "facetas" local e global desse movimento religioso. Depois, apresentarei brevemente os debates a respeito de narrativas e de conversão, e descreverei as maneiras pelas quais os chineses étnicos convertidos relacionam sua nova religião com suas identidades pessoal, de negócios, e de Estado-nação. $\mathrm{N}$ a seção final apresentarei diversas conclusões sobre o papel e o significado da conversão entre os empresários chineses étnicos na Indonésia.

\section{Metodologia de pesquisa}

Em 2004 realizei um trabalho de campo exploratório na cidade de Yogyakarta, na região central de Java, sobre as características dos grupos carismáticos e sobre a vida e o trabalho de vários chineses étnicos renascidos. A escolha de Yogyakarta como local de pesquisa foi muito pragmática: a cidade foi minha base antropológica nos últimos 15 anos. No entanto, como o fenômeno 
é principalmente urbano e Yogyakarta tem uma grande comunidade de etnia chinesa, trata-se de uma cidade tão adequada para esse estudo quanto qualquer outra em Java.

Sendo uma antropóloga organizacional, a maior parte de minha pesquisa consistiu em coletar histórias de vida e trabalho. Conversei detida e repetidamente com chineses étnicos proprietários ou administradores de pequenas e médias empresas sobre questões pessoais, religiosas e sobre negócios, em especial sobre o papel e o significado de suas raízes chinesas em suas vidas pessoal e de negócios, sua educação, o histórico de negócios familiares, as mudanças religiosas pelas quais passaram, e as razões de tais mudanças ${ }^{5}$. Para contextualizar suas narrativas e histórias de conversão, ampliei o âmbito da pesquisa incluindo observação participante nas "igrejas" carismáticas (tanto como participante quanto como observadora), em reuniões do grupo de homens de negócio cristãos, e nas atividades sociais, políticas e de caridade dos chineses étnicos nesta cidade.

Em termos de antropologia organizacional, a pesquisa alia a abordagem antropológica/etnográfica mais tradicional (usada durante encontros dos grupos carismáticos, uma vez que era possível deles participar, observando e fazendo entrevistas) e uma investigação organizacional qualitativa. Para essa última, encontram-se problemas de acesso similares àqueles enfrentados pelos etnógrafos organizacionais quando precisam estar dentro do negócio para estudar os modos pelos quais os gerentes e proprietários "organizam" e "gerenciam" sua empresa (Czarniawska 1998; Dahles 2004). Há, entretanto, boas alternativas a esses obstáculos de acesso, como seguir os empresários e homens de negócios aonde eles podem ser observados (Czarniawska (1998:28) refere-se a essa abordagem como "sombra"): encontros religiosos e todos os tipos de atividades sociais e políticas em que estão envolvidos em função de suas posições como empresários e/ou de sua etnia. Para tal, fui, na maior parte dos domingos, a encontros de igreja (muitas vezes em sessões matutinas e vespertinas, na mesma igreja ou em locais diferentes), mas também a encontros de grupos carismáticos menos populares e a igrejas protestantes mais tradicionais, tentando ser convidada ainda para as outras atividades mencionadas.

Os entrevistados falaram longa e abertamente sobre o papel e 0 significado de sua nova religião em suas vidas profissional e pessoal. A pós uma surpresa inicial, compreendi que, para os cristãos renascidos, contar e recontar as histórias de conversão constitui muitas vezes "um meio de recriar e reconverter o seu ser carismático" (Coleman 2003:17).

Os dados das entrevistas e relatórios de encontros foram sistematicamente analisados, identificando os temas centrais como razões para a conversão e experiências com a fé em suas vidas profissionais. A análise seguiu os métodos qualitativos padrões que partem de uma codificação aberta para uma mais 
seletiva (M iles e H uberman 1994:60-65; Neuman 2000:420-424; Ritchie e Lewis 2004:109-127; 199-217). Isso significa que os tópicos nos quais se organizaram as entradas tornaram-se também ferramentas centrais de análise, onde pôde-se procurar consistências e inconsistências. No entanto, certos temas só vieram à tona após o trabalho de campo, como por exemplo, o fato de que todos os entrevistados participavam ativamente da caridade cristã não tinha sido antecipado.

\section{Chineses étnicos: cidadania, etnicidade e empreendedorismo}

A s histórias, narrativas e depoimentos dos empresários de etnia chinesa nesse estudo só fazem sentido, ou ao menos podem ser melhor entendidos, no contexto onde essa etnia é minoritária, sua cidadania recorrentemente contestada (posição política fraca), mas tem uma posição econômica dominante. A combinação de uma posição politicamente fraca com uma economicamente forte faz desses chineses bodes expiatórios ideais para todos os perigos ou crises que atravessam o Estadonação indonésio. N esta seção, apresentarei rapidamente esse contexto, começando com cidadania e etnicidade, para chegar à posição econômica.

A administração colonial holandesa, em seu tempo, já considerava os etnicamente chineses como "diferentes" e os escolhia como intermediários para os empreendimentos europeus. Esse "status de estrangeiro dos chineses pode ser entendido como o produto ideológico de processos sócio-históricos específicos da Indonésia, especialmente na construção da nacionalidade" (A guilar 2001:505) ${ }^{6}$. A lém de constituírem o maior e economicamente mais poderoso grupo de imigrantes asiáticos, os chineses foram beneficiados com uma parte do lucrativo comércio de ópio, a despeito dos negociantes locais, o que resultou num aumento do fosso entre a população local e os chineses (H efner 2001:17-19). O s europeus faziam uma categorização por etnia: "indígenas malaio-indonésios 'filhos da terra' (malaios, bumiputera, indonésios, pribumi) e 'não-indígenas' ou imigrantes asiáticos (indianos e, especialmente, chineses)" (ibid.:19) Essa categorização assumiu um papel crucial nos anos de formação, tanto na independência quanto mais tarde.

A divisão em europeus, orientais estrangeiros (como os chineses) e pribumi, na qual cada um desses grupos tem direitos específicos, foi criada pelo governo colonial, mas se manteve durante e após a formação do Estado-nação ${ }^{7}$. Kleden (apud Dahana 2004:55) vincula essa estratificação étnica praticada pelos holandeses e herdada pelo governo pós-colonial à interferência governamental. As relações interétnicas, argumenta, transformam-se em inimizade e violência não como conseqüência natural da dominação de um grupo étnico sobre 0 outro, mas principalmente por causa da política governamental enquanto tal.

Desde os meados dos anos 1960 editaram-se várias leis restritivas para os chineses étnicos com 0 intuito de que "tais cidadãos fossem assimilados e que 
a exclusão e discriminação racial fossem evitadas". Entre elas, podemos citar a restrição às expressões tradicionais chinesas, que só podem se manifestar em locais de culto familiares, a exigência da mudança de nomes chineses para nomes indonésios, o banimento da língua e da escrita chinesa de jornais e outras esferas públicas, e a obrigação de trazer sempre consigo uma prova de cidadania indonésia (W inarta 2004:72). A demais, todos os cidadãos indonésios devem possuir uma religião, cuja escolha é restrita entre islamismo, cristianismo, budismo e hinduísmo, o que significa que a adesão ao confucianismo ou outros credos religiosos tradicionais não é permitida. Depois da queda do presidente Suharto (1998), que ficou no poder, governando autoritariamente, durante mais de trinta anos, algumas mudanças foram realizadas, como a revogação da lei sobre a manifestação de expressões culturais e religiosas chinesas ou a instauração do Im Lek (A no Novo chinês) como feriado nacional.

0 mês de maio de 1998 é considerado uma virada na história dos chineses na Indonésia; foi um momento importante devido a violências contra os chineses ${ }^{8}$. A lguns desses chineses tomaram novas iniciativas cidadãs a partir de então, como a formação de partidos políticos, e vários grupos de pressão se fizeram ativos. No entanto, vários argumentam que a maioria deles não participou de nenhumas dessas atividades organizadas e queria simplesmente ser deixado no seu canto "fazendo o que sempre tinham feito tranqüilamente" e "continuar a fazer seus negócios e esperar e rezar para que sua família sobrevivesse a essa crise múltipla" (Tan 2004:35).

Segundo Freedman (2000:117), duas percepções parecem ser ainda preponderantes na Indonésia atual: a idéia de que os de etnia chinesa não são verdadeiros cidadãos e podem abandonar a Indonésia a qualquer momento, e que sempre se beneficiaram desproporcionalmente das oportunidades econômicas oferecidas pelo antigo presidente Suharto e seus parceiros de negócios. Os próprios chineses sentem que "são discriminados, mesmo se têm cidadania indonésia e escolheram o país como Pátria” (Freedman 2000:17).

Em acentuado contraste com seu estatuto de minoria étnica e sua fraqueza política, esses chineses têm posições dominantes em vários setores econômicos. Essa posição avantajada demonstrada com base em dados estatísticos (que já foram objeto de contestações) indicam que os chineses, em termos étnicos, na M alásia, na Indonésia, na Tailândia e nas Filipinas concentram de 40 a 60 por cento do PIB total, assim como cerca de 80 por cento dos ativos empresariais na Indonésia e entre 40 e 50 \% na M alásia (Yeung e O lds 2000:7-9). A explicação desse "sucesso nos negócios" já gerou bastante discussão. Durante muito tempo os argumentos se centravam numa forma típica de capitalismo de rede chinês caracterizado por "qualidades lendárias de empreendedorismo, trabalho duro, frugalidade, solidariedade familiar, educação e outras virtudes 'neo-confucianas' ou 'empresariais'" (M ackie 1998:133). O s meios pelos quais a "identidade étnica 
foi manipulada por indivíduos, grupos e pelo estado para promover seu próprio interesse" (Gomez e Hsiao 2004:36-37) é um debate que está além do alcance deste trabalho. No entanto, os chineses, apesar ou talvez por causa de seu domínio econômico, são também contestados em sua identidade empresarial. Em suma, aos etnicamente chineses na Indonésia não era permitido (pela lei) serem chineses, mas também não Ihes era permitido (pela opinião pública) serem empresários (que era de fato a única opção que Ihes restava para sobreviver após a imigração para a Indonésia).

Do que dissemos pode-se concluir que desde os tempos coloniais os chineses da Indonésia tiveram sua cidadania contestada e foram vistos como "estranhos" bem-sucedidos. 0 Estado ficou longe de se eximir de responsabilidade nessa "criação seletiva e manipulação de identidades étnicas" (Tan 2001:952) em seu esforço de criar uma identidade nacional a partir de uma população multiétnica no processo de construção da nação. Com uma longa experiência de dominação estatal e de discriminação, durante a qual se esforçaram por ser "invisíveis" e seguir seu próprio caminho, a reação dos chineses étnicos é compreensível. Podese supor que o Estado-nação não é mais o espaço no qual eles desejam se engajar, especialmente quando existem outras opções de cidadania como o estatuto de cidadão global ou de cristão global, que permitem encontrar "identidade" e "proteção" para além dos limites territoriais do Estado-nação. Talvez a conversão ao cristianismo global seja exatamente o meio escolhido para isso.

\section{C ristianismo carismático: cultura global e conduta local}

O s cristianismos pentecostal e carismático são considerados os movimentos religiosos com maior crescimento no mundo. 0 termo "cristianismo carismático" refere-se a todos os cristãos, desde os primórdios do cristianismo, destacando especialmente aqueles que partilham "experiências religiosas ou espirituais e atividades do Espírito Santo" (Poewe 1994:2). Esse movimento é caracterizado por "cultos exuberantes, ênfase na experiência religiosa subjetiva e nos dons espirituais, afirmação de milagres, sinais e maravilhas sobrenaturais - incluindo uma linguagem de espiritualidade experiencial mais do que teológica - e uma 'vida no Espírito' mística, através da qual seguem em sua vida cotidiana os desígnios de Deus" (Burgess 2002:xvii). O seu caráter global se assenta no papel cumprido pela mídia (transmissões religiosas), nas redes de irmandades com conexões internacionais, em mega-igrejas que parecem funcionar como corporações internacionais, e em programas de conferências internacionais e orações conjuntas; trata-se de fato de um movimento de caráter transnacional (Poewe 1994:2).

Para alguns autores, uma importante característica que tem passado despercebida no cristianismo carismático é sua "teologia da prática". A teologia 
é realizada e não teorizada, e a pneumatologia é a parte mais proeminente da teologia atualizada (A nderson 2003:8, 2004a:197). Constrói-se assim um sentido de identidade, os 'renascidos' constituindo o povo de Deus, e é a experiência do renascimento que une as pessoas ao redor do mundo (Anderson 2003:8). Os carismáticos "constroem um mundo dentro do mundo, estabelecendo esferas para a ação, a agência e a imaginação que invocam o contexto global de uma maneira específica, 'subcultural'" (Coleman 2000:51-52).

Entre os grupos carismáticas mais bem-sucedidos estão os chamados movimentos saúde e riqueza (evangelho da prosperidade ou teologia da prosperidade). Poewe (1994) e Coleman (2000) destacam que esses movimentos estão se expandindo rapidamente e atraem especialmente a classe média urbana e bem educada. 0 que faz com que tais movimentos se sobressaiam são os três principais domínios de seus ensinamentos: cura, prosperidade e "confissão positiva" (Coleman 2000:28). É também nesses pontos que recebem mais críticas, pois colocariam uma ênfase excessiva na resolução de todos os problemas, sejam de ordem espiritual, corporal ou financeira (Coleman 2000:27). Esses grupos oferecem muitas vezes soluções para problemas coletivos e individuais e se adéquam às necessidades específicas de diversas coletividades socioeconômicas ( $M$ artin apud Hunt 2000:336).

A orientação materialista desses movimentos carismáticos pode ser vista na interpretação que dão para o poder de Deus, que é "reduzido a uma força espiritual que pode ser manipulada de maneira a se apropriar de benefícios materiais" (Hunt 2000:333). Eles encontram terreno fértil em vários países das regiões costeiras do Pacífico, especialmente em países com economias em rápido crescimento, onde expressam uma "nova cultura capitalista", muitas vezes mesclados com formas autóctones tradicionais de religião (Hunt 2000:340).

Os trechos a seguir, extraídos de falas de dois empresários entrevistados de etnia chinesa, vinculam algumas das afirmações mais teóricas acima com a situação do crescente movimento carismático na Indonésia e as relações com um contexto mais global.

0 movimento carismático diz respeito ao Espírito Santo, e se centra na Graça. No começo, o movimento carismático em Yogyakarta teve um bom crescimento; houve vários casos de cura. $M$ as algumas pessoas ficaram arrogantes, e achavam que eram donas, que possuíam o poder, mas o poder é dado às pessoas para que elas o dêem a outras. 0 movimento carismático tem duas faces. Por fora, vemos palmas e cantos; entretenimento com testemunhos exagerados. 0 outro lado é o de dentro, trata-se de conhecer-se a si mesmo e a Jesus, por dentro. É um ensinamento sobre a verdadeira graça e sobre ser abençoado. A teologia do sucesso é um tema espetacular 
e atrai muita gente. 0 princípio de que Jesus vai ajudar está aí. Estes temas espetaculares são bastantes populares na Indonésia hoje em dia. Eu fico mais satisfeito com temas que tentam resolver problemas. Homens de negócios também encontram problemas, tentam encontrar uma solução, e acham que podem encontrar nesse credo. Mas essa não é uma base sólida para sua crença. Se alguma outra coisa acontecer eles podem facilmente abandonar a fé.

A globalização exige um modo mais expressivo. Eu acredito que, nesse mundo global, fazer negócios pode ser mais seguro com 0 cristianismo, com nossa fé. Um verdadeiro cristão é protegido em seus negócios. No mundo dos negócios, quando não estamos envolvidos com o Senhor, as coisas podem dar errado.

O s carismáticos asiáticos se caracterizam pela compreensão literal da Bíblia como a "Palavra de Deus", e por uma preferência acentuada por uma busca de salvação pessoal e muitas vezes individualista. Muitos se envolvem em evangelização pessoal (A nderson 2005:2). 0 movimento pentecostal-carismático na região é tido como "jovem", pois foi bem depois dos anos 1950 que começou a atrair seus primeiros seguidores. Esse rótulo também se aplica aos seguidores atuais, que são jovens atraídos pelo estilo de culto "moderno", com cantos agradáveis. O movimento asiático é também tido como revelador de uma "espiritualidade asiática única", e de uma "mensagem mais positiva e relativa a este mundo, em contraste com o caráter predominantemente pessimista ou mesmo escapista do pensamento cristão" (M a 2005:61-67). Questões cotidianas, como necessidades pessoais ou do negócio, ou a cura, ocupam o centro das atenções.

A história pentecostal (carismática) da Indonésia começa nos anos 1910/ 1920 com a chegada dos missionários holandeses que deram origem à I greja Pentecostal da Indonésia ( $\mathrm{GPdl}$ ), a maior denominação pentecostal. 0 movimento pentecostal teve sucesso, mas foi limitado por vários cismas, e em 1924 já havia mais de 50 grupos denominacionais. A partir da GPdl nasceu uma das maiores congregações, a I greja Indonésia Bethel (GBI), que passou de 51 mil membros em 1970 a 420 mil nos anos 1990 (W iyono 2005:312:313). São essas igrejas de Bethel que conhecerem um "crescimento quantitativo tremendo" nos últimos anos, com congregações que vão de alguns milhares até 70 mil membros (W iyono 2005:317). Essas igrejas caracterizam-se por uma estrutura organizacional descentralizada, isto é, são autônomas, seguem um estilo de culto divertido (cantores, músicos, grupos de dança), com uma pregação pragmática animada com piadas, histórias e testemunhos, feita por pregadores que são antigos homens de negócios, profissionais liberais ou celebridades, contam com um marketing agressivo e enfatizam o miraculoso, como a cura divina (Wiyono 2005:318-319). 
U ma nova subdivisão da Igreja Bethel, Betani, cresceu muito rapidamente nos anos 1990, com dezenas de milhares de pessoas participando dos cultos em cidades javanesas. Ela apresenta todas as características dos movimentos saúde e prosperidade, com destaque para "sinais e maravilhas, evangelismo de massa, culto high-tech, marketing moderno e métodos de crescimento da igreja que levam a um alto número de conversões" (Robinson 2005:338). Durante esse tempo houve um crescimento explosivo de mega-igrejas nos centros de negócios das principais cidades da Indonésia (Wijaya 2002:259).

0 movimento pentecostal-carismático indonésio conheceu até hoje dois períodos de rápido crescimento. A primeira explosão teve lugar no final dos anos 1980 como conseqüência do processo acelerado de modernização, industrialização, desenvolvimento econômico e islamização, particularmente nas regiões urbanas de Java. Alguns autores sustentam que os novos grupos religiosos, como 0 movimento carismático, preencheram o vácuo ideológico que o rápido processo de modernização criou. N esses anos o influxo de aderentes vinha principalmente da classe média, de profissionais liberais e de homens de negócio (Robinson 2005:337-338). o segundo momento de crescimento, às vezes descrito como exponencial, foi registrado com o começo da crise econômica e a queda do presidente Suharto em 1997/1998 (e as várias insurreições - e ataques contra os cidadãos chineses étnicos - que ocorreram). Em 1998 o movimento pentecostalcarismático contava entre 7 e 9 milhões de pessoas; em 2001, chegou a 11 milhões, e em 2002 considera-se que o número seja de 12 milhões. Isso representa cerca de 5 a 6 por cento da população indonésia e representa um crescimento anual de cerca de 3,5 por cento (Robinson 2005:340).

Além do mencionado vazio ideológico que teria sido preenchido pelos movimentos carismáticos, outras possíveis razões para tal crescimento na Indonésia seriam a natureza secular e transformadora do movimento, sua aparência moderna, suas experiências sobrenaturais (curas, libertações, dons do Espírito Santo) envolvendo sonhos e visões, a ênfase dada a um relacionamento pessoal com Jesus Cristo com garantia da salvação pessoal através de Jesus Cristo e a crença no poder da Bíblia e do Espírito Santo de transformar vidas. A demais, os encontros são abertos para todos, e seguem um padrão freqüentemente muito simples e pouco formal, como encontro de oração, cultos da igreja, lições da Bíblia sobre questões da vida cotidiana, encontros de reavivamento, encontros "grupos celulares" (cell groups), programas especializados para mulheres, jovens e homens de negócios, e assim por diante. É um movimento moderno, caracterizado por uma liderança forte (Robinson 2005:340-342).

0 contexto específico da Indonésia não deve ser deixado de lado, como o domínio sociopolítico do Islão (principalmente na ilha de Java), a história de perseguição de cristãos e de igrejas (sendo as igrejas pentecostais o principal alvo dos ataques no final dos anos 1990 e começo dos anos 2000), e o fato de 
que muitos cristãos provêm das comunidades minoritárias de etnia chinesa ( Goh 2005:60-62).

O $s$ dois movimentos carismáticos estudados na presente pesquisa pertencem à corrente Bethel/Betani supramencionada e se assemelham aos movimentos saúde e prosperidade. A mbos contam com cerca de 2500 seguidores locais, a maioria deles chineses étnicos jovens e de classe média. Ilustramos a seguir um encontro dominical comum.

0 recinto está cheio de cadeiras, acolhendo entre 400 e 500 pessoas. No palco uma banda (guitarra, baixo elétrico, bateria, teclado) está se aprontando; dois homens e duas mulheres com microfones nas mãos estão se balançando ligeiramente em nossa frente. U ma mulher jovem sobe e desce do tablado. A trás dela, duas dançarinas de cada lado, usando vestidos brancos e verdes. A parede do fundo tem uma faixa onde se lê: 10000 almas, 1000 grupos celulares. Ao entrar no recinto, todos recebem um boletim semanal contendo um envelope branco, que obviamente será recolhido mais tarde. 0 recinto começa a encher, especialmente com jovens chineses. A lguns minutos depois de 8h30, a música fica mais alta, e a mulher jovem, que se revela a líder do culto, começa a cantar e a falar, incitando os participantes a repetir e acompanhar. Em questão de minutos todos estão de pé, a música está mais alta e as pessoas se aproximam. Durante a primeira hora, cantam-se canções com textos como "amamos nosso Senhor" ou "Jesus é o nosso Senhor". A líder do culto é muito eficiente; sempre que nos pede que aplaudamos, que apertemos as mãos dos vizinhos ou que estendamos os braços para o céu em direção a Jesus, todos obedecem. Depois de quase uma hora, um homem é chamado à frente para nos contar uma história. Em 20 a 30 minutos, esse homem de negócios chinês relata seus problemas pessoais: seu pai era um jogador inveterado, seus negócios estavam endividados, sua mulher não conseguia engravidar e ele mesmo confessa ter sido uma pessoa bastante egoísta. Em 1997 começou a seguir Jesus, e em 2000 foi batizado e se tornou um cristão renascido. Durante o testemunho, o teclado toca suavemente, e a audiência escuta com um ar de aprovação. É a história de alguém em dificuldades na vida pessoal e de negócios que encontrou Jesus: seus problemas financeiros foram resolvidos e ele e sua mulher têm agora um bebê. Depois do testemunho, o pregador toma a palavra para reflexões bíblicas sobre o perdão e o amor. Durante mais 30 minutos ele relata várias histórias reais cotidianas, mostrando como a crença em Deus é proveitosa. No meio tempo ele canta e brinca 
com 0 auditório, que reage às suas piadas; ele mistura as línguas, javanês, indonésio e chinês, e no final de sua pregação faz todos levantarem novamente, cantando e batendo palmas. Quando 0 encontro termina, o pregador e seu estafe ficam à disposição para cumprimentar os espectadores na saída. (Relatório de observação Domingo, 5 de setembro de 2004; Yogyakarta 08h30 - 10h30)

Em ambas as congregações os pregadores são etnicamente chineses. Em resposta à pergunta sobre 0 porquê de serem principalmente chineses que vão a esses encontros, um dos pregadores dá uma resposta muito simples mas reveladora, que mostra a divisão étnica ainda presente na sociedade indonésia: "se o pregador é chinês, haverá muitos chineses presentes". E acrescenta:

eles também vão à igreja carismática por que há mais liberdade para expressar seu louvor, seu amor por Deus, é mais dinâmico, há mais liberdade. Temos, entre nossos membros, muita gente que trabalha duro a semana toda. Ficam muito cansados. Se eles têm de ir à Igreja no domingo, esperamos que possam encontrar diversão. Eles precisam relaxar e encontrar alegria e alívio em Deus, de maneira que possam voltar para suas famílias e para suas vidas depois da Igreja com uma força renovada.

o que tentam alcançar, segundo um dos líderes da igreja, é:

deixar as pessoas prontas para ver Jesus frente a frente. Queremos fazer com que as pessoas tenham consciência de Deus e da palavra de Deus. Focamos então principalmente nos ensinamentos da Bíblia, mas de uma maneira moderna. Para que as pessoas não achem muito difícil de entender, fazemos a relação com as suas vidas cotidianas. A plicamos esses ensinamentos às suas vidas. Como Deus pode nos ajudar a resolver nossos problemas e a sermos fortes?

\section{A abordagem narrativa e a conversão}

A maior parte das histórias coletadas contém um elemento de mudança pessoal radical associado com problemas pessoais ou de negócios que levaram 0 narrador à conversão, a se tornar um cristão renascido. Houve bastante debate acadêmico sobre a utilização de narrativas, histórias contadas, e/ou histórias de vida nas ciências humanas e sociais, mas a maior parte dos autores concorda que a forma narrativa é a forma mais básica que os seres humanos utilizam para dar sentido às experiências". N as palavras de Polkinghorne, "o significado narrativo é um processo 
cognitivo que organiza as experiências humanas em episódios temporalmente significantes... que usamos para explicar nossas ações e as dos outros" (1988:1).

A s narrativas aqui estudadas são analisadas levando em conta que as narrativas são interpretações retrospectivas, "depois do fato", de ações, eventos e acontecimentos de nossas vidas, constituindo um ato de significação (cf. Geertz 1995). A s histórias de vida e de negócios são analisadas relacionando elementos das diferentes histórias, tais como problemas pessoais e de negócios e a conversão, a fenômenos partilhados pelo conjunto do grupo, como a delicada posição dos etnicamente chineses no Estado-nação indonésio.

Denzin (1989:22) introduz o termo "epifanias", ou momentos de virada, para defender a idéia de que a maior parte dos textos biográficos se estrutura em torno de pontos significativos da vida do narrador. As epifanias podem ser úteis para entender de que forma os momentos intensos ou "decisivos" numa vida acabam por dar o tom aos demais momentos, como pode ser o caso para a virada religiosa na vida dos chineses estudados aqui. "Epifanias são momentos interacionais e experiências que deixam marcas nas vidas das pessoas. $\mathrm{N}$ elas, 0 caráter pessoal é manifestado. São muitas vezes momentos de crise. A Iteram as estruturas de significação fundamentais da vida da pessoa" (Denzin 1989:70).

Tomar a conversão como uma epifania não resolve o problema do significado que dá às vidas das pessoas ou do que expressa. Há uma abundante literatura sobre conversão, mas sua definição "é uma das tarefas mais árduas e desnorteantes para os estudiosos, assim como para os religiosos" (Rambo 2000) ${ }^{10}$. 0 estudo clássico de Snow e M achalek (1984) sobre a explicação da conversão cobre um amplo leque de fatores, de mudança psicológica pessoal radical (stress, privações) a interpretações mais sociológicas de atributos sociais (idade, classe, educação) e influências sociais (redes sociais, interação intensiva). Trabalhos posteriores sobre conversão, especialmente por parte de historiadores e etnógrafos, enfatizaram a necessidade de incluir o contexto social e cultural mais amplo no qual os indivíduos mudam de religião, sem por isso desprezar os fatores psicológicos (Yang 2005). A partir daí, Hefner (1993:4) defende o estudo da "conversão em toda a sua complexidade - sociológica e histórica, cultural e psicológica", entendendo a maneira pela qual "processos sociais e individuais interagem no tempo". Essa abordagem sintética foi escolhida, por exemplo, por Kipp (1995:872), que usa a teoria da prática para "ver como a agência dos indivíduos reproduz ou muda os sistemas mais amplos nos quais agem esses indivíduos".

0 papel dos mercados religiosos e dos fatores institucionais também deveria ser levado em conta, particularmente em tempos de globalização. 0 componente institucional acrescenta o fato de que a religião também se tornou uma mercadoria e que as organizações religiosas se tornaram importantes fornecedoras nos mercados religiosos (Yang 2005). Esses mercados são aprovisionados pelos movimentos carismáticos, com sua semelhança a companhias transnacionais. 
Portanto, o que os estudos recentes sobre conversão têm em comum é a certeza de que a conversão não pode ser compreendida a partir de um único fator, seja ele a experiência individual ou o contexto social, político ou institucional. A conversão deve ser vista como "continuada e praticada", como uma "passagem" e uma "resposta a dilemas intelectuais e práticos" (A ustinBroos 2003:9).

A releitura das histórias de vida e de negócios dos empresários chineses estudadoa que se converteram de várias religiões (particularmente do protestantismo e do budismo) parece mostrar que a conversão é tanto uma experiência pessoal intensa ligada a momentos de problemas pessoais e profissionais quanto um fenômeno social e político (posições de cidadania e étnicas contestadas). Na próxima seção, essa afirmação será fundamentada.

\section{$\mathrm{N}$ arrativas de conversão: identidades valorizadas?}

0 que revelam as narrativas de experiências de conversão a respeito do porquê os etnicamente chineses (empresários) converterem-se ao cristianismo pentecostal-carismático? Q uais são as motivações pessoais, mas também sociais, políticas e institucionais nesse caso? Como o artigo começou com a afirmação de que o grupo estudado tem uma situação precária no Estado-nação indonésio, com um longo histórico de contestação de identidade como etnicamente chineses, como atores políticos e econômicos, e com pouca margem para sua expressão cultural (fator que vem sendo revertido há pouco tempo), discutirei a seguir a conversão carismática em dois níveis. No primeiro nível, abordarei as questões mais amplas de etnicidade, contestação e globalização, e no segundo voltar-meei para o lado mais pessoal, as experiências individuais dos chineses aqui em estudo.

\section{Valorizando identidades étnicas e globais?}

No contexto indonésio, a virada carismática entre os de etnia chinesa funde componentes étnicos, de classe e econômicos. No entanto, os acontecimentos mais gerais na Indonésia e fora dela cumprem um papel importante nessa "fusão". Durante os anos 1980 e 1990, a Indonésia conheceu uma miríade de mudanças, como os rápidos processos de modernização, industrialização, urbanização e a islamização, mas também uma grave crise econômica da qual está se recuperando lentamente. Nesses anos uma vibrante cultura de consumidores e uma "classe média considerável" se desenvolveram juntamente com um "vácuo ideológico", com espaço para "novos valores e estilos de vida", como oportunidades para novos movimentos religiosos (Robinson 2005:338). Parece ter sido um momento histórico em que várias linhas de 
desenvolvimento se cruzaram. Primeiro, as classes médias (urbanas) eram as mais suscetíveis de serem atingidas pelas novas ofertas dos mercados religiosos globais (internet). É "a posição única das classes médias no mercado religioso global que lhes permite valer-se dos recursos oferecidos por redes internacionais para sincretizar ideologias salvacionistas com experiências locais" (Lee e Ackerman 1997:143-144). Segundo, naquele momento grandes igrejas internacionais começaram uma campanha bem-sucedida para catequizar os de etnia chinesa (Brazier 2006). Finalmente, os líderes dos novos movimentos realmente não estão isolados; estão literalmente conectados com os acontecimentos globais. Um bom exemplo é fornecido pelo depoimento a seguir, de um pregador de um movimento carismático em Yogyakarta (cujo pai, mencionado na citação abaixo, lidera um movimento similar na cidade de Solo):

Q uando começamos a crescer em 1995, aprendemos com Yonggi Cho, da Coréia. De Solo, o pregador deão foi para a Coréia. Os deões de nossa igreja estão muito interessados em aprender com outras igrejas. Em 1997, outra viagem foi feita, para Cingapura, para a igreja de Lawrence Khong. Em 1999, meu pai foi para Bogotá (Colômbia), onde se encontra o maior movimento carismático: a M issão Carismática Internacional (ICM). Desses e de outros obtivemos o que se chama de método G-12 ou, como chamamos aqui, 'grupos celulares', em que as 'células' se multiplicam. Fomos os primeiros na Indonésia a trabalhar com esse método de grupos celulares. Em Solo, o número de células cresceu de 273 para 1125 em 5 meses.

Entre essas circunstâncias concorrentes, encontra-se um elemento étnico específico. O cristianismo pentecostal-carismático parece ter sucesso especialmente entre minorias étnicas estigmatizadas como inferiores, onde "age como uma revitalização e uma afirmação de integridade moral" (M artin 2005:28). Nessa ótica, a religião atua não somente como criadora de identidade, mas expressa ao mesmo tempo uma nova potência. Isso parece ser aplicável ao caso dos etnicamente chineses da Indonésia. As seguintes citações de entrevistas mostram claramente a existência de sentimentos profundamente arraigados de uma identidade chinesa suprimida.

Q ueremos reafirmar a idéia de que a cultura chinesa é muito bonita. 0 s últimos 30 anos na Indonésia deixaram um saldo de desconhecimento dos valores e da cultura chinesa. Q ueremos mudar isso para a próxima geração. Os chineses que emigraram para diferentes partes do mundo conseguiram sobreviver e obter sucesso por causa de sua cultura, de sua moral e de sua confiança interpessoal. 
É chegado o dia para os chineses de começarem a dar valor a sua identidade, a se envolver na política prática. É a hora. M as devemos ser cuidadosos para não incorrermos em excessos, não podemos exagerar. Por identidade, refiro-me à inteligência, a valores culturais; somos pessoas que contam. $M$ as não devemos nos mostrar com vinte Mercedes. Embora seja tempo para os chineses de mostrar sua identidade, não devemos fazer disso um espetáculo. 0 que podemos fazer é reafirmar nossos valores em alto e bom som: espiritualidade, polidez e normas sociais e culturais.

U m dos maiores problemas é o estatuto da educação na Indonésia. Dá-se muita atenção ao Q I, deixando de lado a educação moral e social. M uitos não entendem isso. M as os chineses entendem. Para mim, os chineses sempre estiveram sob pressão, e pessoas sob pressão muitas vezes conseguem melhores resultados.

As narrativas apontam para duas questões: 0 desejo de reconhecimento por parte dos chineses como uma etnia chinesa e o caráter global dos movimentos pentecostal-carismáticos. 0 primeiro ponto é obviamente relacionado ao fato de que por mais 30 anos as pessoas de ascendência chinesa tiveram de negar suas raízes étnicas (e valores culturais) por causa da política do Estado que pretendia "total assimilação". 0 caráter global desses movimentos carismáticos - o segundo ponto - parece ser propício ao ressurgimento do grupo étnico chinês suprimido. Proponho, portanto, a hipóteses de que há interdependência entre esses processos. No nível mais abstrato, a opção por uma religião claramente ocidental e global pode ser interpretada como uma "fonte de resistência simbólica" (Coleman 2000:40). A escolha expressa, nesse contexto majoritariamente não cristão, tanto um afastamento do Estado-nação quanto a definição por um quadro de referência mais amplo e cosmopolita. Como expressado anteriormente, o cristianismo carismático não somente corresponde bem às novas demandas da globalização (as experiências religiosas vibrantes desses movimentos carismáticos se adéquam bem ao ritmo acelerado no novo mundo), como também oferece proteção, especialmente para os homens de negócio etnicamente chineses. Raciocinando a partir daí, podemos imaginar que esse fenômeno global traz um sentido novo ou diferente para o pertencimento a um espaço nacional desacreditado e opressor. Talvez prefiram ser primeiro e principalmente cristãos carismáticos que pertencem a uma comunidade global e como tal adotar uma visão de si mesmos como cidadãos de um mundo sem fronteiras, como uma família dentro da família maior de Deus, e "as igrejas cristãs têm relações com poderosos agrupamentos internacionais que defendem ardorosamente os direitos das minorias cristãs em todo o mundo" (Brazier 2006). Nas palavras de um dos entrevistados: 
Se olharmos os fatos, podemos dizer que no passado os chineses se sentiam como um povo intimidado. Eles se sentiam como um grupo deixado de lado, que não tinha nenhuma oportunidade. Tinham medo, e eram aterrorizados por outros. É exatamente por isso que foram em busca de justiça, amor, perdão, espiritualidade, proteção, Deus. Daí por diante começaram a ser abençoados.

\section{Valorizando a identidade empresarial?}

Por relevante que seja o contexto apontado acima, a conexão mais importante se encontra no que os etnicamente chineses relatam sobre seu "ser" cotidiano, em suas famílias e em seus negócios, onde ser um chinês e fazer negócios é quase uma relação biunívoca. No nível individual, o cristianismo carismático, com seu "estilo de culto agradável" e sua "pregação pragmática" (W iyono 2005:318) oferece tanto distrações quanto soluções imediatas para os problemas cotidianos. Um dos entrevistados expressou essa idéia nos seguintes termos:

Eventos sobrenaturais são sentidos nos encontros. 0 s problemas que chegam ao palanque para receberem preces são problemas em casa, entre marido e mulher, e problemas com negócios.

O s testemunhos, em particular, que são centrais nos encontros e nos livros e panfletos produzidos, oferecem exemplos prontos, e tais exemplos não podem ser encontrados nas igrejas mais tradicionais. Todos os entrevistados no meu estudo dirigiram-se ao cristianismo carismático em momentos de distúrbios (muitas vezes relacionados à família ou aos negócios) e muitos se referem aos ataques aos chineses e à crise econômica de 1998, como a seguir:

A ntes da crise, eu tinha encomendado um lote de material da fábrica, mas a entrega não foi feita; ao mesmo tempo os preços estavam aumentando por causa da crise. Meus filhos diziam: 'não confie só na sua força, confie em Jesus'. Um dia, meus filhos me levaram para a igreja e lá eu comecei a chorar. Fiquei com vergonha, mas não conseguia me controlar. Nesse ponto eu estava pronto para entregar minhas preocupações a Jesus, e levantei as mãos. Subimos todos ao tablado e levantamos nossas mãos juntos. Eu senti como uma descarga elétrica nos meus dedos, deu-me vontade de gritar, foi uma sensação muito boa.

$\mathrm{N}$ esse meio tempo os negócios estavam se acelerando, os preços aumentavam constantemente. M as eu fiquei calmo, sabia que Jesus cuidaria disso. Quando os preços alcançaram seu nível máximo, 
minhas mercadorias finalmente chegaram, e o mais estranho foi que, apesar dos preços altos, vendi todos os produtos.

Chama a atenção o papel dos problemas empresariais e de negócios no encontro com Jesus; esses problemas específicos funcionam de fato como os instigadores da conversão. Embora questões familiares também sejam mencionadas, a virada é quase sempre relacionada a problemas graves nas atividades econômicas.

Eu estava envolvido em um negócio muito lucrativo. Tinha se tornado um estilo de vida para mim, mas não era um negócio 'limpo'. Durante a crise em 1999 a situação financeira piorou. Comecei a preocupar-me com dinheiro, especialmente para sustentar a família. Tive muitos problemas, e sentia que não podia falar com ninguém. Comecei a rezar a Deus para que me ajudasse com esses problemas. Rezei muito, dei tudo o que estava em meu coração para Deus e disse: 'Deus, eu quero crer, ter fé'. E tive resposta. Foi também o momento em que deixei aquele negócio. Estar junto com D eus não significa que não temos mais problemas, mas eles estão na Sua mão, nós estamos sob Sua liderança. (Ele tornou-se um renascido em 1999)

0 encontro com Jesus é para muitos uma libertação, muitas vezes de fardos específicos. Os depoimentos expressam que encontrar Deus e ser capaz de acreditar em sua correção e liderança torna-se um guia importante na vida cotidiana. Eles contam que abandonam seus problemas e preocupações financeiras nas mãos desse Todo-Poderoso. 0 que expressam como uma rendição completa. Encontram paz interior, e de fato parece que encontram benefícios em suas vidas pessoal e de negócios; essa religião dá-lhes força e poder.

Depois de encontrar Deus tenho muito mais facilidade em meu negócio. A ntes de encontrar Deus, conduzia meu negócio com a cabeça, com um pensamento racional, tentando ser o mais perfeito possível. Pensava que dessa maneira teria melhores resultados. $M$ as depois de muitas experiências difíceis e negativas eu acolhi Jesus no meu coração. Rezo todos os dias antes de começar a trabalhar. Coloco o dia nas mãos de Deus, e o que quer que aconteça é o que Deus quis que fosse. Encontrei paz nisso. A ntes, gastava muito tempo agradando a consumidores. Todas as noites pensava sobre 0 negócio, e não conseguia dormir. $M$ as depois de meus encontros com Deus isso não é mais um problema, tudo está em Suas mãos. 
Em seu estudo sobre religião e economia, Wijaya (2002) explica o caso de empresários chineses ativos em uma igreja protestante indonésia. 0 cristianismo apresenta certos atrativos para os chineses, como uma correspondência entre certas crenças religiosas populares chinesas e valores cristãos. Entre esses últimos, o mais importante é 'a família'. Esse conceito de 'familismo' é, segundo Wijaya, a pedra angular da vida econômica, política, social e cultural-religiosa dos chineses étnicos. No entanto, as mensagens dessa igreja tradicional e a interpretação dessas mensagens pelos homens de negócios em sua atividade econômica não aprimoram seu espírito para os negócios. É onde o movimento carismático se mostra diferente, e onde muitos empresários chineses parecem encontrar suas respostas; "em contraste com o budismo ou o catolicismo, as igrejas carismáticas endossam a acumulação de riqueza - uma mensagem que é atraente para um grupo que tem no dinheiro uma proteção numa sociedade turbulenta e volátil" (Brazier 2006). A lém da atenção explícita dada, no movimento carismático, a todas as questões empresariais, o estilo pessoal do culto, a relação "direta" com Deus, e o espaço aberto para questões e problemas cotidianos parecem se adequar à vida desses chineses étnicos de classe média que, em suas vidas de empresários, carregam o pesado fardo de serem os únicos responsáveis pelo sucesso de seus negócios. Os depoimentos expressam uma vontade de não mais estar 'só'.

U ma tal identidade empresarial (tão freqüentemente contestada na história da Indonésia) é ainda fortalecida pelo papel de uma rede de crentes. Para grupos religiosos minoritários que são em alguma medida excluídos da sociedade, 0 "acesso a conselhos e serviços profissionais através das redes religiosas ou étnicas pode ter conseqüências não desprezíveis" (Dodd e Seaman 1998:73). O s empresários religiosamente ativos constroem muitas vezes laços pessoais de confiança com fiéis do mesmo credo: "a rede reforça as normas comportamentais da fé, e também fornece uma fonte fundamental de contatos para 0 indivíduo" (Dodd e Seaman 1998:73). Os empresários no meu estudo usaram todos extensivamente as redes pessoais, em geral com outros da etnia chinesa, argumentando que compartilham com esses normas de negócios que são diferentes daquelas dos empresários locais, mas também se referem a sua história comum (migração) e finalmente, devido a, simplesmente, muitos dos negócios empresariais estarem nas mãos dos próprios chineses. No entanto, dentro da rede mais recente de fiéis do mesmo credo, a etnicidade e a religião parecem se fundir e, além de possíveis novos parceiros comerciais poderem ser encontrados aí, o mais importante parece ser a revalorização de sua identidade empresarial. Há em todo caso um papel para os pastores dos movimentos carismáticos, como mostra o seguinte exemplo, de um encontro de empresários etnicamente chineses em espetáculos em Yogyakarta. 
A Bíblia tem muitos versículos que mostram que desde o princípio homens de negócio contribuíram para o trabalho do Senhor e para a difusão da palavra. M uitos dos próximos a Jesus eram empresários e o cristianismo cresceu no mercado. Isso não foi uma coincidência. Desde o começo, o Senhor viu os negociantes como um grupo abençoado; de fato, o Senhor queria que eles difundissem sua mensagem. Em suas atividades de negócios eles podem servir a Deus e prover de cuidados celestiais as pessoas a sua volta, conduzindo seus negócios de maneira cristã, não explorando seus trabalhadores, trabalhando honestamente e usando o seu lucro para ajudar a desenvolver o trabalho de Deus. A ssim, os homens de negócios devem acreditar que são escolhidos, e que o Senhor thes dará o poder de continuar Seu trabalho.

Embora Weber tenha sugerido que a acumulação de capital foi uma conseqüência não intencional do "chamado" combinado com uma ética puritana (Weber 1930), não podemos falar de "não intencional" no caso da acumulação de capital dos chineses convertidos ao cristianismo deste estudo. Há, sim, um apelo muito consciente por orientação espiritual e apoio de Deus.

\section{C onclusão}

0 objetivo deste artigo era desvendar o interessante fenômeno do crescente número de chineses, em termos étnicos, na Á sia que se convertem ao cristianismo carismático. Focando a atenção nos chineses na Indonésia, este artigo tentou encontrar uma resposta à questão de porque isso acontece com esse grupo específico. A abordagem narrativa foi usada como ferramenta para entender melhor o significado que esses convertidos atribuem à sua experiência de conversão. Essa abordagem é usada para revelar a maneira pela qual os chineses entrevistados falam de sua nova religião a partir de sua perspectiva pessoal, étnica e profissional.

Como conclusão, sustento que a atração que o movimento carismático exerce sobre os chineses na Indonésia deve ser explicada por fatores de impulsão e de atração. A impulsão desses chineses urbanos, empreendedores, pertencentes às classes médias para o cristianismo carismático pode ser interpretada em termos de libertação e de aumento de potência. U ma libertação de sua posição específica de minoria étnica que, como a história mostrou, é uma posição muito insegura. No entanto, ao mesmo tempo, o movimento carismático é um forte fator de atração, pois sua insistência nos aspectos seculares parece se adequar particularmente bem a esse grupo de empresários, fornecendo uma identidade global e moderna que compõe com sua posição econômica - e que também os 
coloca em posição de aproveitar o mercado religioso global no qual os novos movimentos religiosos estão ativos ao mesmo tempo em que encontram orientação espiritual. 0 movimento carismático é único entre os movimentos religiosos por seu evangelho da prosperidade; a criação de riqueza é encorajada (mas não somente para o bem-estar pessoal), alcançando assim o "coração" dos empresários deste estudo. M ais importante é o fato que Ihes fornece um espaço onde podem compartilhar suas inseguranças e seus problemas de negócios com outras pessoas de pensamentos semelhantes. Há cuidado e alívio; os encontros com companheiros cristãos, na maior parte dos casos de mesma etnia, trazem apoio material e imaterial. Os fatores de impulsão e atração reforçam suas múltiplas identidades (muitas vezes contestadas) de empresários, chineses e cristãos.

Essas são as conclusões se tomamos a abordagem narrativa como uma ferramenta analítica. Entretanto, em um contexto mais amplo é importante lembrar que o cristianismo carismático é um movimento global, conhecido por "difundir o evangelho da prosperidade" tanto em termos internacionais como em cada bairro. Em função de tais conexões entre o local e o global, membros individuais podem se sentir conectados aos crentes de todo o mundo, não somente partilhando o evangelho mas ainda uma posição social e um estilo de vida. Para os etnicamente chineses da Indonésia que se voltaram para 0 cristianismo carismático, essa conexão com uma comunidade global pode ter um significado especial. Pode reduzir sua insegurança política e oferecer uma saída em uma situação deprimente em que seu sucesso econômico e financeiro não corresponde a uma posição de participação no poder político. Em outras palavras, sua participação em um movimento carismático, ao fornecer-Ihes uma identidade religiosa global, permite-Ihes desligarem-se do sistema político opressivo e do tratamento iníquo de seu próprio Estado-nação, pondo-se sob a proteção do cristianismo global. A renovação da vida espiritual, a preferência pela experiência em detrimento do dogma, e o oferecimento de soluções para os problemas cotidianos constituem uma resposta e uma expressão da modernidade, pósmodernidade e globalização (cf. Walter e Hunt 1998).

A suposição de que o estatuto de renascidos desses chineses convertidos constitui uma nova identidade talvez seja exagerada, mas pode-se argumentar de que o "ser renascido" é o elo que une de maneira legítima e segura suas identidades que de outro modo seriam mais contestadas. 


\section{Referências bibliográficas}

A GUILA R, Filomeno. (2001), "Citizenship, Inheritance, and the Indigenizing of 'O rang C hinese' in Indonesia". Positions, 9(3): 501-533.

A NDERSON, A lan. (2003), "The Proliferation and Varieties of Pentecostalism in the Majority World". C onferência no Symposium N on-Western Pentecostalism, A msterdam.

. (2004a), A n Introduction to Pentecostalism. G lobal Charismatic Christianity. Cambridge: Cambridge University Press.

(2004b), "Writing the Pentecostal H istory of A frica, A sia and Latin A merica". Journal of Belief and Values, 25(2): 139-151.

. (2005), "The Charismatic Face of Christianity in A sia". In: A. A nderson e E. Tang (eds.) A sian and Pentecostal. The Charismatic Face of $\mathrm{C}$ hristianity in A sia. Oxford: Regnum Books International.

ATKIN SO N, Robert. (1998), The Life Story Interview. Qualitative Research M ethods Series 44. A Sage U niversity Paper. Londres: Sage Publications.

A USTIN-BRO OS, Diana. (2003), "The Anthropology of Conversion: An Introduction". In: A. Buckser e S. D. Glazier, (eds.) The Anthropology of Religious Conversion. Lanham: Rowan \& Littlefield Publishers.

BOJE, D avid M. (2001), N arrative M ethods for O rganizational \& Communication Research. Londres: Sage Publications.

BRA ZIER, Roderick. (2006), "In Indonesia, the Chinese go to Church". International H erald Tribune, Quinta-feira, 26 de abril de 2006.

BRUNER, Jerome. (1990), A cts of M eaning. Cambridge: Harvard University Press.

BURGESS, S.M . ed. (2002), T he N ew International Dictionary of Pentecostal and C harismatic M ovements. M ichigan: Zondervan.

CA SA N O VA, Jose. (2001), "Religion, the N ew M illennium, and G lobalization". Sociology of Religion, inverno de 2001, 62: 415-441.

CHA N KW O K-BUN. (2004), "Preface". In: T. M enkhoff e S. Gerke, (eds.) C hinese Entrepreneurship and A sian Business N etworks. Londres, Nova Iorque: Routledge.

COLEMA N, Simon. (2000), The G lobalization of Charismatic Christianity. Spreading the Gospel of Prosperity. Cambridge: Cambridge University Press.

. (2003), "Continuous Conversion? The Rhetoric, Practice and Rhetorical Practice of Charismatic Protestant Conversion". In: A. Buckser e S. Glazier, (eds.). The A nthropology of Religious Conversion. Lanham: Rowan \& Littlefield Publishers.

COPPEL, Charles. (2003), "Special Issue Foreword". A sian Ethnicity, 4(3): 327-336.

CZA RN IA W SKA , Barbara. (1998), A N arrative A pproach to 0 rganization Studies. Q ualitative Research M ethods Series 43. A Sage University Paper. Londres: Sage Publications.

DA HANA, A . (2004), "Pri and N on-Pri Relations in the Reform Era: A Pribumi Perspective". In: L. Suryadinata, (ed.) Ethnic Relations and $\mathrm{N}$ ation-Building in Southeast A sia. The case of the Ethnic C hinese. Singapore: ISEA S Publications.

DA H LES, H eidi. (2004), Ethnographies of O rganizations. Contestory Process and Contested M ethod. A presentação no seminário: The Ethnography of $O$ rganizations: the Inside 0 ut? D epartamento de Cultura, O rganização e Gerenciamento, V rije U niversiteit A msterdam (dezembro de 2004).

DEN ZIN , N orman K . (1989), Interpretive B iography. Q ualitative Research M ethods Series 17. A Sage U niversity Paper. Londres: Sage Publications.

DODD, Sarah \& SEA M A N , Paul. (1998), "Religion and Enterprise: A n Introductory Exploration." Entrepreneurship: Theory and Practice, 23(1): 71-86.

FREEDM A N, A my. (2000), Political Participation and Ethnic M inorities. Chinese 0 verseas in M alaysia, Indonesia and the U nited States. Londres, Nova Iorque: Routledge. 
GA BRIEL, Yiannis. (2000), Storytelling in 0 rganizations. Facts. Fictions, and Fantasies. 0 xford: 0 xford University Press.

GEERT Z, Clifford. (1995), A fter the Fact. Two C ountries, Four D ecades, 0 ne A nthropologist. Cambridge: $\mathrm{H}$ arvard U niversity Press.

GO H, Robbie. (2004), "A sian Christian N etworks. Transnational Structures and Geopolitical M appings". Journal of Religion and Society, 6:1-13.

(2005), C hristianity in Southeast A sia. Singapore: ISEA S Press.

GOM EZ, Terence \& HSIA O , M icheal. (2004), "Introduction: Chinese Business Research in Southeast

A sia". In: T. Gomez e M. H siao (eds.). C hinese Business in Southeast A sia. Contesting C ultural

Explanations, Researching Entrepreneurship. Londres, Nova Iorque: RoutledgeC urzon.

H EFN ER, Robert. (1993), "World Building and the Rationality of Conversion". In: R. H efner, (ed.).

Conversion to Christianity. H istorical and A nthropological Perspectives on a $\mathrm{G}$ reat Transformation.

Berkeley: University of California Press.

(1998), "Introduction: Society and M orality in the new A sian Capitalisms". In: R.

$\mathrm{H}$ efner, (ed.). M arket C ultures. Society and M orality in the $\mathrm{N}$ ew A sian $\mathrm{C}$ apitalisms. Boulder Colorado: Westview Press.

(2001), "Introduction: Multiculturalism and Citizenship in M alaysia, Singapore, and Indonesia". In: R. H efner, (ed.). The Politics of M ulticulturalism. Pluralism and Citizenship in $M$ alaysia, Singapore, and Indonesia. H onolulu: U niversity of Hawai'i Press.

HU NT, Stephen. (2000), "'W inning Ways': G lobalisation and the Impact of the Health and Wealth Gospel". Journal of C ontemporary Religion, 15(3): 331-347.

. (2003), A Iternative Religions. A Sociological Introduction. Hampshire: A shgate.

HUNT, S., HAMILTON, M. \& WALTER, T. (1997), "Introduction: Tongues, Toronto and the

M illennium". In: S. Hunt, M. Hamilton e T. Walter (eds.), Charismatic C hristianity. Sociological

Perspectives. H ampshire: M acmillan Press Ltd.

KIPP, Rita Smith. (1995), "Conversion by Affiliation: The History of the Karo Batak Protestant Church". A merican Ethnologist, 22(4): 868-882.

LEE, Raymond \& A CKERM A N, Susan. (1997), Sacred Tensions. M odernity and Religious Transformation in M alaysia. Columbia: University of South Carolina Press.

LIEBLICH, A mia, TUVAL-MASHIAC, Rivka \& ZILBER, Tamar. (1998), N arrative Research. Reading, A nalysis, and Interpretation. A pplied Social Research $M$ ethods Series volume 47. Londres: Sage Publications.

MA, W. (2005), "A sian (Classical) Pentecostal Theology in Context". In: A. A nderson e E. Tang (eds.). A sian and Pentecostal. The $\mathrm{C}$ harismatic Face of $\mathrm{C}$ hristianity in A sia. $\mathrm{O}$ xford: R egnum Books International, 59-92.

M A CKIE, Jamie. (1998), "Business Success among Southeast A sian Chinese: the Role of Culture,

Values and Social Structures". In: R. Hefner, (ed.). M arket Cultures. Society and M orality in the N ew A sian C apitalisms. Boulder, Colorado: Westview Press.

M A RTIN, D avid. (2005), "Issues A ffecting the Study of Pentecostalism in A sia". In: A. A nderson

e E. Tang, (eds.) A sian and Pentecostal. The Charismatic Face of Christianity in A sia. Oxford:

Regnum Books International.

MILES, M.B. e HUBERMAN, A.M. (1994), Q ualitative Data A nalysis. A n Expanded Sourcebook.

Londres: Sage Publications, 2a edição.

N EU M A N, W.L. (2000), Social Research M ethods. Q ualitative and Q uantitative A pproaches. N eedham H eights: Allyn \& Bacon, 4a edição.

PLU M M ER, Ken. (2001), D ocuments of Life 2. A n Invitation to a C ritical H umanism. Londres: Sage Publications.

POEW E, Karla. (1994), "Introduction: The N ature, Globality, and H istory of Charismatic Christianity".

In: K. Poewe, (ed.). Charismatic C hristianity as a G lobal Culture. Columbia: University of South

Carolina Press. 
POLKINGHORNE, Donald E. (1988), N arrative Knowing and the Human Sciences. Nova Iorque: State U niversity of $\mathrm{N}$ ew York Press.

RA M BO, Lewis. (1999), "T heories of C onversion: U nderstanding and Interpreting Religious Change". Social Compass, 46(3): 259-271.

episódio no- 411.

(2000), Conversion - Part 1. Religion and Ethics Newsweekly, 10 de novembro,

[http://www.pbs.org/wnet/religionandethics/week411/rambo.html].

REID, A nthony. (ed.) (1996), Sojourners and Settlers: H istories of Southeast A sia and the C hinese. St Leonard's: A llen \& Unwin.

RICHIE, J., e LEW IS, J. (2004), Q ualitative Research Practice. A Guide for Social Science Students and Researchers. Londres: Sage Publications.

RO BBIN S, J. (2004), "T he G lobalization of Pentecostal and Charismatic Christianity". A nnual Review of A nthropology, 33: 117-143.

RO BIN SO N, M ark. (2005), "T he Growth of Indonesian Pentecostalism". In: A. A nderson e E. Tang, (eds.) A sian and Pentecostal. The C harismatic Face of Christianity in A sia. Oxford: Regnum Books International.

SIDDIQ UE, Sharon. (2003), N ew Light on Indonesia's Ethnic M akeup. Book Review for Viewpoint ISEA S (http://www.iseas.edu.sg/viewpoint/ssmay03.pdf - baixado em 23 de junho de 2005).

SN O W, David A. e M A CH A LEK, Richard. (1984), "T he Sociology of Conversion". A nnual Review of Sociology, 10: 167-190.

SODERBERG, A nne-M arie. (2003), "Sensegiving and Sensemaking in an Integration Process; A $\mathrm{N}$ arrative A pproach to the Study of an International A cquisition". In: B. Czarniawska e P. Gagliardi (eds.). N arratives we 0 rganize. A msterdam/Philadel phia: John Benjamins Publishing Company.

STARKE, Rodney \& FINKE, Roger. (2000), A cts of Faith. Explaining the Human Side of Religion. Berkeley: University of California Press.

SUSA NTO, A ndreas. (2006), "Safety-First. Strategies of M anaging Insecurities among Chinese Indonesians in Yogyakarta". In: J. Koning e F. H üsken (eds.) Ropewalking and Safety N ets. Local Ways of $M$ anaging Insecurity in Indonesia. Leiden, Boston: Brill

TA N, Eugene. (2001), "From Sojourners to Citizens: Managing the Ethnic Chinese Minority in Indonesia and Malaysia". Ethnic and Racial Studies, 24(6): 949-978.

TA N, M ely. (2004), "Unity in Diversity: Ethnic Chinese and N ation-Building in Indonesia". In: L. Suryadinata, (ed.) Ethnic Relations and N ation-Building in Southeast A sia. The Case of the Ethnic C hinese. Singapore: ISEA S Publications.

TURNER, Victor \& BRUNER, Edward (eds.). (1986), T he A nthropology of Experience. U rbana and Chicago: U niversity of Illinois Press.

VATIKIO TIS, M ichael. (2005), "H eavens, A sia's going C hristian". A sian Times [http://www.atimes.com/ atimes/Southeast_A sia/H C 02A e03.html]

WA LTER, Toney e HUNT, Steve. (1998), "Introduction: The Charismatic Movement and Contemporary Social Change". Religion, 28: 219-221.

W EBER, Max. (1995/1930), T he Protestant Ethic and the Spirit of C apitalism. Londres, N ova Iorque: Routledge.

W IJA YA, Yahya. (2002), Business, Family and Religion. Public Theology in the C ontext of the $C$ hineseIndonesian Business Community. Bern: Peter Lang A G.

W IN A RTA, Frans. (2004), "Racial Discrimination in the Indonesian Legal System: Ethnic Chinese and N ation-Building". In: L. Suryadinata, (ed.) Ethnic Relations and N ation-Building in Southeast A sia. The case of the Ethnic C hinese. Singapore: ISEA S Publications.

W IYO N O, Gani. (2005), "Pentecostals in Indonesia". In: A. A nderson e E. Tang, (eds.) A sian and Pentecostal. The Charismatic Face of Christianity in A sia. Oxford: Regnum Books International.

YA N G, F. (2005), "Lost in the Market, Saved at M CD onald's: Conversion to Christianity in U rban China". Journal for the Scientific Study of Religion, 44 (4): 423-441. 
YEUNG, Henry e OLDS, Kris (eds.) (2000), G lobalization of C hinese Business Firms. H ampshire: $M$ acmillan Press Ltd.

\section{N otas}

1 Essa é uma versão revista do artigo publicado na Conferência Internacional sobre Religião e Deslocamentos: Estudos Comparados; Programa Paulo Freire, Grupo de Pesquisa sobre Religião. Universidade do Estado de Rio de Janeiro, Rio de Janeiro, 4-6 de Setembro de 2006. Eu gostaria de agradecer à D ra. M arjo de Theije pelo convite para participar da conferência e por possibilitar minha viagem e estadia no Rio de Janeiro através do Programa Paulo Freire da V U U niversity A msterdam. M inha gratidão também para os dois revisores anônimos, por seus valiosos comentários sobre 0 artigo.

20 adjetivo "carismático" é usado ao longo do texto para referir-se às igrejas e aos movimentos pentecostais, que se caracterizam pela importância atribuída ao dom (carisma, em grego) do Espírito Santo. A pesar do hábito brasileiro de reservar o termo para a corrente católica Renovação Carismática, optei por manter o termo original (N. do T.).

3 Há uma ampla variedade de termos usados para se referir aos grupos e igrejas relacionados ao pentecostalismo. A Iguns chegam a afirmar que "cada uma das milhares organizações representa um tipo específico entre as igrejas Pentecostais e Carismáticas" (A nderson 2004a:9). 0 pentecostalismo tem origem na tradição evangélica protestante (metodistas, batistas) e em seus movimentos Santidade no século XIX. O pentecostalismo nasceu na "renovação da A zusa Street" (1906-1909) em Los A ngeles; a glossolalia é a evidência material do batismo do Espírito Santo. A teologia pentecostal insiste em que "Jesus oferece a salvação, Jesus cura, Jesus batiza com o Espírito Santo e Jesus voltará", e esse padrão de "Evangelho Completo" da teologia pentecostal penetrou numa ampla gama de contextos culturais ao redor do mundo (Robbins 2004:121). A maior parte da literatura especializada inclui no movimento carismático "as igrejas das denominações reconhecidas que sofreram influências pentecostais pela dinâmica da Renovação Carismática, assim como os ministérios e organizações para-eclesiásticas fora dessas estruturas" (H unt, H amilton e Walter 1997:2). Casanova (2001:435) argumenta que o cristianismo pentecostal/carismático é "o setor do cristianismo protestante com crescimento mais rápido no mundo" (2001:435). N este artigo, usarei os termos cristianismo pentecostal-carismático e cristianismo carismático para me referir à forma específica de cristianismo que está em discussão (pois os grupos, movimentos e igrejas referidos na pesquisa têm suas raízes em denominações protestantes pentecostais).

4 Embora centre minha análise nos empreendedores chineses étnicos na Indonésia, isso não implica afirmar que não há outros grupos étnicos que se convertam ou que somente os proprietários de negócios mudem de religião. No entanto, entre os convertidos, os homens e mulheres chineses étnicos que são ativos em negócios são especialmente bem representados, fato esse que demanda uma maior exploração das dimensões étnica, econômica e religiosa envolvidas.

5 Entrevistei mais empreendedores homens do que mulheres. N os negócios familiares chineses mais tradicionais, os homens são os representantes principais das empresas. M uitas vezes, suas mulheres e filhas também são ativas no negócio (cuidando da contabilidade ou dos contatos com clientes), mas são invisíveis na maior parte do tempo; esse é um tema de pesquisa que requer mais atenção.

6 Regulamento 1946 permitiu que os chineses nascidos na Indonésia se tornassem cidadãos indonésios. Foi necessário um esclarecimento posterior por parte das autoridades locais para estabelecer que 0 ato permitia que os chineses peranakan assumissem a cidadania indonésia, mas não os chineses nascidos fora da Indonésia, ou totok (Freedman 2000:101).

7 Para uma análise mais extensa, ver Reid (1996), A guilar (2001), H efner (2001) e Tan (2001).

8 Ver Coppel (2003) e especialmente o volume especial de Etnicidade asiática (vol. 4. n. 3; 2003) que discute a diversidade de reações da população chinesa na Indonésia após a queda de Suharto. 
9 É importante destacar autores, entre outros, Turner e Bruner (1986), Polkinghorne (1988), D enzin (1989), Bruner (1990), A tkinson (1998), Czarniawska (1998, 2004), Lieblich et al (1998), Gabriel (2000), Boje (2001), Plummer (2001), e Sonderberg (2003), que já trabalharam o tema.

${ }^{10}$ Essa é uma questão já bastante trabalhada pela literatura e não se pode deixar de fazer referência a, por exemplo, Snow e Machalek (1984), H efner (1993), Kipp (1995), Rambo (1999), Stark e Finke (2000), H unt (2003), e Yang (2005).

\section{Juliette Koning (jbm.koning@fsw.vu.nl)}

Conferencista do Departamento de Cultura, O rganização e Gerenciamento da VU U niversity A msterdam e coordenadora do programa Sudoeste A siático da Faculdade de Ciências Sociais. Detém um PhD em antropologia social pela Universidade de A msterdam (1997) sobre migração campo-cidade na Indonésia. Sua pesquisa atual se concentra em religião, etnicidade, identidade e empreendedorismo na Indonésia. Entre suas obras publicados estão Women and $\mathrm{H}$ ouseholds in Indonesia, C ultural $\mathrm{N}$ otions and Social Practices (2000), N atural Resources and Social Security (2001), G enerations of C hange (2004) e Rope Walking and Safety N ets: Local Ways of M anaging Insecurity in Indonesia (2006). 


\section{Resumo:}

0 rápido crescimento do cristianismo pentecostal-carismático na Á sia e a participação da população etnicamente chinesa nesse crescimento levantam a questão sobre em que medida a adesão a essa crença tem se tornado parte de uma identidade étnica chinesa. No contexto de uma discussão mais ampla sobre 0 apelo global do cristianismo carismático, o presente artigo foca a situação da Indonésia, um país em que a maioria da população é muçulmana. 0 objetivo desse estudo é revelar a maneira pela qual os chineses "cristãos nascidos de novo" dão sentido a suas experiências de conversão.

Palavras-chave: cristianismo carismático, conversão, cidadania, identidade, etnia chinesa.

\section{A bstract:}

The current upsurge of Pentecostal-charismatic Christianity in A sia and the participation of ethnic $C$ hinese therein, raise the question whether the adherence to charismatic belief has become part of an ethnic C hinese 'identity'. In the context of a more general discussion on the global appeal of charismatic Christianity, this paper zooms in on the situation in Indonesia a country where the majority population is M uslim. The aim is to come to an understanding of the manner in which the $\mathrm{N}$ ew Born Christian Chinese in this study give meaning to their conversion experiences.

Keywords: charismatic Christianity, conversion, citizenship, identity, ethnic Chinese. 